\title{
Studying the impact of construction dewatering discharges to the urban storm drainage network(s) of Doha city using infoworks integrated catchment modeling (ICM)
}

\author{
Mohammed Sameer ${ }^{1,}$, and Rabee Rustum ${ }^{2}$ \\ ${ }^{1}$ WorleyParsons Qatar, Al Wosail Tower, West Bay, Doha, Qatar \\ ${ }^{2}$ Heriot Watt University, Dubai International Academic City, Dubai, UAE
}

\begin{abstract}
The discharge of construction dewatering flows to the storm drainage network for disposal is a common activity in Qatar. The Dupuit empirical approach was utilized to establish various hypothetical dewatering scenarios on the basis of site classifications, which were modeled on 4 Case Study Areas of Doha's Existing Surface Drainage Network in order to study the impact of dewatering discharge against an established baseline. The simulations were undertaken using InfoWorks Integrated Catchment Modeling (ICM) software for critical and non-critical rainfall events. The results indicated significant localized flooding in excess of the baseline conditions for scenarios exceeding $0.5 \mathrm{~m}^{3} / \mathrm{sec}$ flows, while individual catchments demonstrated variations and sensitivities on the basis of catchment properties and rainfall events. It is evident that dewatering discharge under unpredictable rainfall events poses various levels of risk to the city's infrastructure, which is further exacerbated due to the massive scale of construction activity in the country and the rising ground water table in Greater Doha Area basin.
\end{abstract}

\section{Introduction}

Although the groundwater tables in Qatar have been depleting in its two major inland basins, namely the northern and southern basins, the Doha basin area has seen a significant increase in the groundwater table [1]. This is primarily due to two major reasons, the first is due to rapid urbanization, causing land use changes \& over-irrigation using treated wastewater (TSE) [2, 3], the second is due to increased saline intrusion from the sea [1, 4]. Land use changes for Doha were further studied by Hashem and Balakrishnan between 1997 to 2010 [5]. The resulting rise of Groundwater table in the Doha basin has yilded increased dewatering flows at construction sites in Doha, as well as flood incidences for larger projects, such as the Doha Metro [6].

The overseeing Authority for Drainage Infrastructure in Qatar, the Public Works Authority, ASHGHAL presently recommends, the following four disposal options for

\footnotetext{
* Corresponding author: $\underline{\mathrm{ms} @ \text { msameer.engineer }}$
} 
construction dewatering flows, as prescribed in The Construction Dewatering Guidelines, Qatar [7]:

1. Discharge to sea via Surface and Groundwater Network

2. Direct Discharge to Sea

3. Discharge to lagoons (covered by geotextile is preferred or else lagoon not covered by geotextile).

4. Discharge by re-injection (Deep Aquifer Recharge).

According to the guidelines, Option 1 - Discharge to sea via Surface and Groundwater Network is described as the most common practice in Qatar. However, on small scale projects, direct discharge to the sea or re-injection may not be feasible or cost effective. These flows are usually discharged to the sea or inland lagoons via the storm water drainage network [8].

The practice of disposal of dewatering discharge via the storm-sewer lines is not new. Cox III [9] in his study of dewatering of a construction site in a semi-urban area suggested tapping into the Storm Sewer lines for disposal of construction dewatering discharges. More recently, this practice of disposal to sewer/storm drains has become quite common in many urbanized areas where other disposal options are limited or cost prohibitive. Dewatering practices in Qatar, including the Construction Dewatering Guidelines of Qatar have been formed by adapting parts of various regulations, on the basis of their applicability in Qatar.

Hydraulic modelling tools, such as InfoWorks CS have been used regularly to assess the overflows and flooding of combined sewers [10]. However there hasn't been any significant research undertaken in regards to studying the impacts of construction dewatering flows on the surface network under an active rainfall event in order to assess potential back flooding, overflows or exacerbation of existing sensitive flooded areas.

\section{Methodolgy}

\subsection{Dewatering Discharge Flows for Doha: Field Data vs Empirical Estimation}

Dewatering discharge data was obtained from KOOP Water Services Qatar through site visits, for two sites of the Doha Metro Project, the Al Azizyah and Sports City stations of the Gold line. The steady state pumping readings for two subsequent days to maintain current drawdown depths were obtained for each site, which were used to dereive the daily dewatering discharges. For comparison, the dewatering discharge for both the sites is estimated using the Dupuit-Forchhiemer [11-13] approach using the given properties. The properties of these sites, the daily discharge readings and the empirical estimations are summarized in Table 1 below.

Using the Dupuit-Forchheimer approach, the theoretical discharge estimation is very close to the actual discharge flowmeter readings from the sites, as shown in Table 1. It should also be noted that for the Al Azizyah station the estimation is slightly higher than the actual. The degree in variation arises due to various factors from the hydraulic conductivity to the fluctuations in the water table as a result of ongoing dewatering. However overall the DupuitForchheimer approach can be utilized to accurately estimate the flows in gross quantities, with a high degree of accuracy. 
Table 1: Site Properties for Al Azizyah and Sports City Metro Stations.

\begin{tabular}{|c|c|c|}
\hline Site Property & Sports City Station & Al Azizyah Station \\
\hline Excavation Area $\left(\mathrm{m}^{2}\right)$ & 12,768 & 7,200 \\
\hline Ground Elevation (m) QNHD & +21.00 & +18.5 \\
\hline $\begin{array}{l}\text { Existing Ground water level (m) } \\
\text { QNHD / m BGL }\end{array}$ & $+15.95 / 5.05$ & $+11 / 7.5$ \\
\hline $\begin{array}{l}\text { Maximum Excavation level (m) } \\
\text { QNHD / m BGL }\end{array}$ & $-9.65 / 30.65$ & $-4.7 / 23.2$ \\
\hline $\begin{array}{l}\text { Ground water level required (m) } \\
\text { QNHD / m BGL }\end{array}$ & $-10.65 / 31.65$ & $-5.7 / 24.2$ \\
\hline Total Drawdown required (m) BGL & 26.6 & 16.7 \\
\hline $\begin{array}{l}\text { Average Hydraulic Conductivity, K } \\
(\mathrm{m} / \mathrm{s})\end{array}$ & $3.11 \times 10^{-05}$ & $10^{-05}$ \\
\hline $\begin{array}{l}\begin{array}{l}\text { Flowmeter Reading on } \\
\left(\mathrm{m}^{3} / \text { day }\right)\end{array} \\
\end{array}$ & $2,250,699(18 / 03 / 2016)$ & $702,895(25 / 06 / 2015)$ \\
\hline $\begin{array}{l}\text { Flowmeter Reading on Day } 2 \\
\left(\mathrm{~m}^{3} / \text { day }\right)\end{array}$ & $2,257,877(19 / 03 / 2016)$ & $704,073(26 / 06 / 2015)$ \\
\hline $\begin{array}{l}\text { Daily Discharge (Day } 1 \text { - Day } 2) \\
\left(\mathrm{m}^{3} / \text { day }\right)\end{array}$ & 7,178 & 1,178 \\
\hline $\begin{array}{l}\text { Estimation using Dupuit- } \\
\text { Forchheimer Approch (m³/day) }\end{array}$ & 7,486 & 2,066 \\
\hline
\end{tabular}

\subsection{Design Storm Events: Rainfall Data for Qatar}

The average annual rainfall in Doha, measured at Doha International Airport from 1962 to 2011 is $76.6 \mathrm{~mm}$ [14]. The analysis of surface drainage networks are commonly done by utilizing 'Design Rainfall' data. These are derived from the IDF curve for the particular region. For Qatar, the current recommended IDF curve is based on the research by Bazaraa and Ahmed for the rainfall dataset available from DIA from 1962-1989 [15]. Since then the IDF has been updated due to availability of further data [14].

\subsection{Baseline Model Overview: Hydrology and Hydraulics}

The Storm Water Model for the Existing Surface Drainage Network in Doha city was obtained from the Public Works Authority - Ashghal, Qatar. The model was built in InfoWorks CS as a 1D model, consisting of piped networks, pumps, reservoirs, outfalls and catchments. The entire model has multiple catchments and outfalls, which have been modelled individually as part of various projects and combined into a large central model.A total of 4 selected catchment areas were simulated for this study.

To run an extensive study comprising of various scenarios and simulations, the model was converted to an InfoWorks ICM model in order to utilize ICM's improved functionalities such as the Scenario Manager and the Group Run Scheduler. The Scenario Manager and the Run Scheduling tools were effectively employed to create over 20 different scenarios for each Case Study Area (CSA) model, and run a total of $800+$ unique simulations. The model for each CSA was simulated using their existing parameters and no changes were made with the exception of the addition of dewatering flows as per the defined scenarios. 


\subsection{Overall model parameters:}

Combined, the 4 CSA's consists of approximately 738 ha of public realm area comprising of roads, plots and network elements. These elements consists of a total of 1670 nodes, 1660 pipes, 5 outfall, 2 storage tank, 6 penstocks (modeled as sluice), 3 screens, 3 weir, 7 pumps and 670 sub-catchments.

All the pipes have the Colebrook-White attribute associated with them, for estimating the frictional losses. The majority of the pipes have a roughness value of $1.5 \mathrm{~mm}$ and $3 \mathrm{~mm}$ assigned, which is acceptable given the networks in the model are not new [3]. Some pipes also have roughness of $0.6 \mathrm{~mm}$, indicating newer pipes.

\subsection{Case Study Areas: Approch \& Considerations}

The 4 studied Case Study Area's are presented in Figure 1 and further described briefly in table 2 .

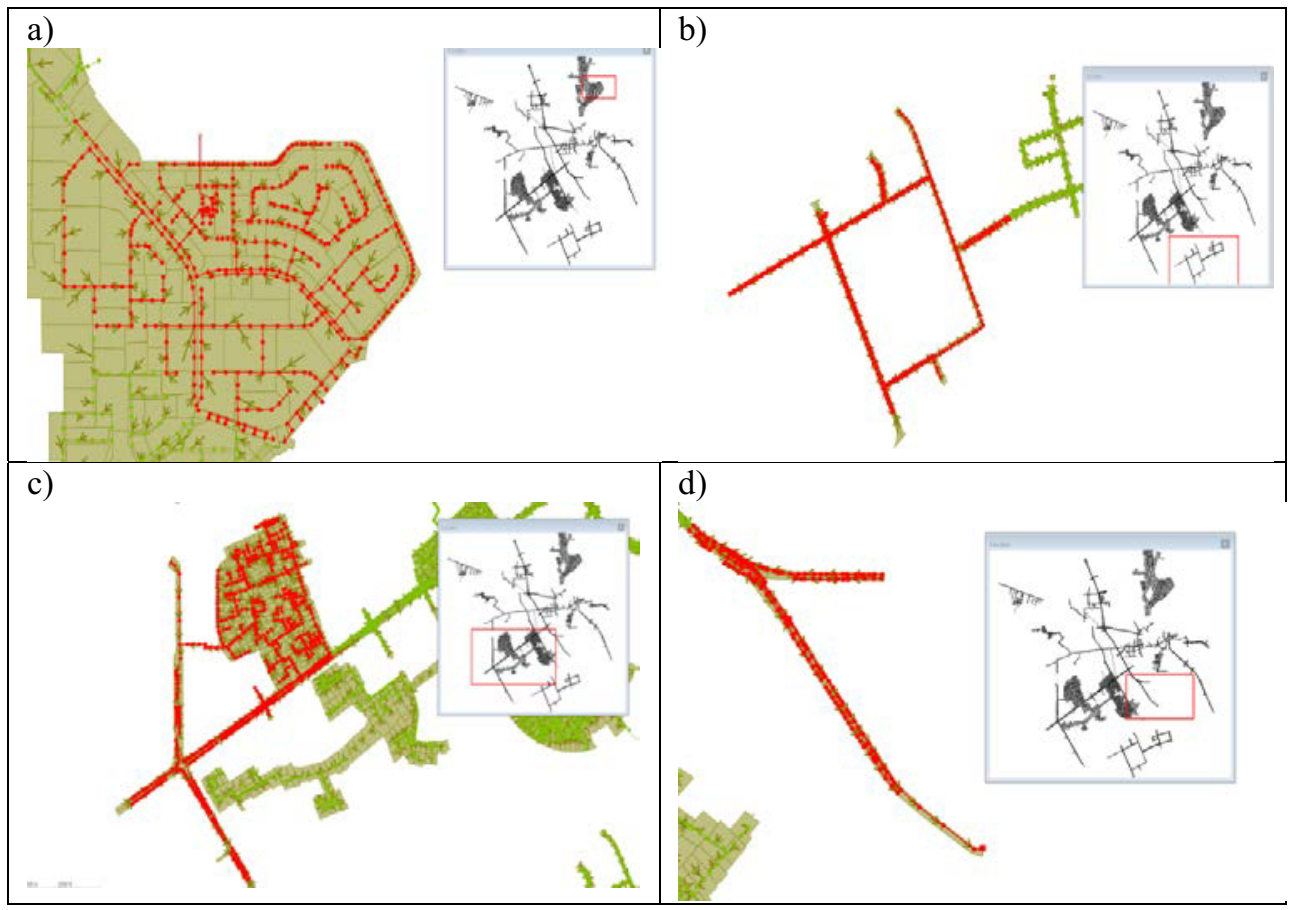

Fig. 1: Model View for a) CSA 1 - West Bay Catchment, b) CSA 2 - Barwa City Catchment, c) CSA 3 - Al Azizya Subcatchment and d) CSA 4 - Section of Doha Expressway.

Table 2: Description of Case Study Areas.

\begin{tabular}{|l|l|l|l|ll|}
\hline & CSA 1 & CSA 2 & CSA 3 & CSA 4 \\
\hline Water Table & High $(1-5 \mathrm{~m})$ & Average (5-7m) & Average (5-7m) & High (3-7m) & Residential \& \\
\hline Land use & $\begin{array}{l}\text { Highrises, } \\
\text { Commercial, with } \\
\text { Basements }\end{array}$ & $\begin{array}{l}\text { Residential } \\
\text { Complex } \\
\text { Commercial }\end{array}$ & $\begin{array}{l}\text { Mixed Residential } \\
\text { \& Commercial } \\
\text { Commercial }\end{array}$ & \\
\hline $\begin{array}{l}\text { Catchment } \\
\text { Type }\end{array}$ & Roads and Plots & Roads Only & Roads and Plots & Expressway Only \\
\hline Discharge & To Sea via Outfall & $\begin{array}{l}\text { To Lagoon via } \\
\text { Outfall }\end{array}$ & To Sea via Outfall & $\begin{array}{l}\text { To Lagoon via } \\
\text { Outfall }\end{array}$ \\
\hline
\end{tabular}




\subsection{Location of dewatering sites:}

A total of 3 new redundant Subcatchments are added to each CSA to simulate the Dewatering scenarios. The Subcatchments are labelled as Site1, Site2 and Site3. The hypothetical scenario site Subcatchments are located on actual empty plots within CSA catchment area. The flows are added as 'tradeflow' to each site, corresponding to the simulated scenarios and discharge is allocated to the nearest manhole in the catchment.

Subcatchment 'Site1' is simulated for all the single site scenarios. In these simulations, all the other sites have no flows assigned to them and are rendered inactive. The location of 'Site1' in all the CSA are on the empty plot farthest from the outfall. This enables the dewatering flows to remain longer in the system and travel through longer lengths of pipes within the network. The scenarios were built and assigned to the relevant Sites using the 'Scenario Manager' function of InfoWorks ICM. Overall, there are a total of 20 scenarios simulated for each CSA per storm event, 10 for low $\mathrm{K}\left(3 \times 10^{-5}\right)$ and 10 for average $\mathrm{K}\left(5 \times 10^{-}\right.$ $\left.{ }^{4}\right)$. This brings out a total of $20 \times 4 \times 9=720$ scenarios across the 4 CSA areas or 180 dewatering scenarios per Case Study Area. These scenarios do not include the initial baseline runs.

\section{Results and analysis}

The model was run for a total of 16 rainfall events to analyze and define the baseline conditions, prior to the addition of any dewatering flows. These events and the flood analysis of the baseline model runs are shown in Table 3 for flooding above the kerb level. The results in the baseline model are only considered for the Case Study Areas.

Table 3: Number of flooded nodes above kerb level for Baseline Model (Combined)

\begin{tabular}{|c|c|c|c|c|}
\hline Duration/Frequency & $\mathbf{1 5}$ Minutes & $\mathbf{3 0}$ Minutes & $\mathbf{6 0}$ Minutes & $\mathbf{1 2 0}$ Minutes \\
\hline $\mathbf{1}$ in 2 years & 1 & 4 & 7 & 5 \\
\hline $\mathbf{1}$ in 5 years & 3 & 23 & 52 & 49 \\
\hline $\mathbf{1}$ in 10 years & 15 & 59 & 131 & 85 \\
\hline $\mathbf{1}$ in 25 years & 56 & 142 & 193 & 182 \\
\hline
\end{tabular}

The results of the baseline model run shows flooding in all the case study areas for all durations of 1 in 25 year storm event. Majority of the flooding is in CSA 1 and 3, while CSA 2 and 4 indicated negligible baseline flooding. It was also observed that the flooding peaks for the 60 minutes duration storms. The number of flooded nodes can be seen receding for the 120 minutes duration rainfall. This is observed for all rainfall frequency events. The least flooding was observed in 15 and 30 minutes duration storms for 1 in 2,1 in 5 and 1 in 10 year events.

It is clear that the 60 minutes duration storm is critical storm for the baseline model, having the most number of flooded nodes. Similarly 15 and 30 minutes duration storms are non-critical but will cause flash floods. The 1 in 25 year frequency storms have been observed to be severe for all durations. The 120 minutes duration storms are non-critical and are excluded for dewatering scenarios. Furthermore the PWA Ashghal lists the basis of these storm events and their associated flood protection requirements, as illustrated in Table 4 below [16].

It is understood that if a rain event causes flooding in the catchment, any additional flows will only further exacerbate the flooding, thus 1 in 25 year storm events are also excluded from the study. Based on the results of the baseline runs, the model is re-run with the subsequent dewatering scenarios for only the critical and non-critical events, i.e., for 15,30 and 60 minutes durations of the 1 in 2 years, 1 in 5 years and 1 in 10 years frequency storm 
events. The baseline is used as a benchmark to study the impact of dewatering flows under the same rainfall events.

Table 4: Flood Protection Criteria for Various Areas in Qatar [16].

\begin{tabular}{|c|l|}
\hline \multicolumn{1}{|c|}{ Event } & \multicolumn{1}{|c|}{ Area } \\
\hline $\mathbf{1}$ in $\mathbf{2}$ Years Storm & Parks, Playgrounds, natural areas and minor roads \\
\hline $\mathbf{1}$ in 5 Years Storm & Low cost housing, Major roads \\
\hline $\mathbf{1}$ in $\mathbf{1 0}$ Years Storm & $\begin{array}{l}\text { Government, institutional and other office developments, } \\
\text { technically sensitive property, basements, power equipment, } \\
\text { High cost housing }\end{array}$ \\
\hline $\mathbf{1}$ in 25 Years Storm & High prestige or Ceremonial development \\
\hline
\end{tabular}

For analysis, the results were further constructed as column charts on the basis of total number of flooded nodes for both baseline and dewatering scenarios. This sorting of data resulted in 3 charts for each CSA, with each chart illustrating the impact of dewatering discharge in comparison to the baseline for the respective storm event frequencies. These charts and their subsequent analysis for CSA 1 is presented below.

\subsection{Analysis of CSA-1 Dewatering Scenarios}

The run result graphs for CSA 1 - West Bay Catchment is presented in Figure 2 to Figure 4 below.

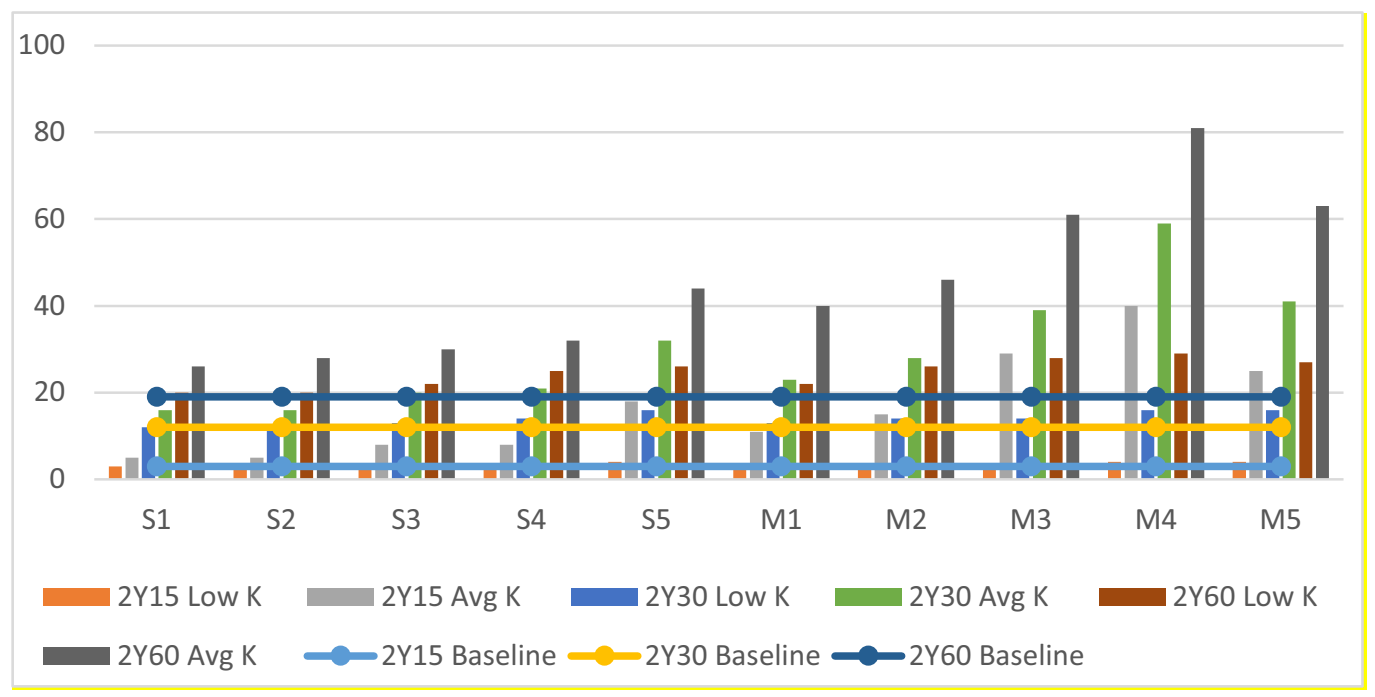

Fig. 2: Number of Flooded Nodes for CSA 1 - 2 Year Storm Events. 


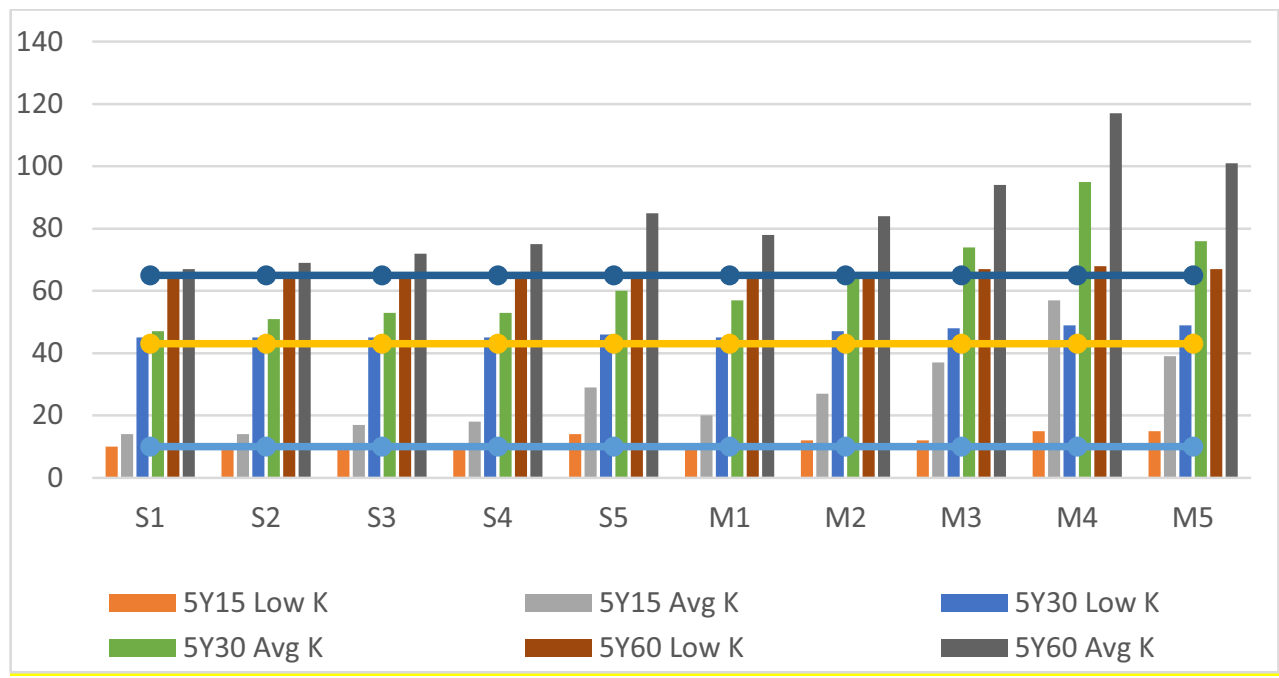

Fig. 3: Number of Flooded Nodes for CSA 1 - 5 Year Storm Events

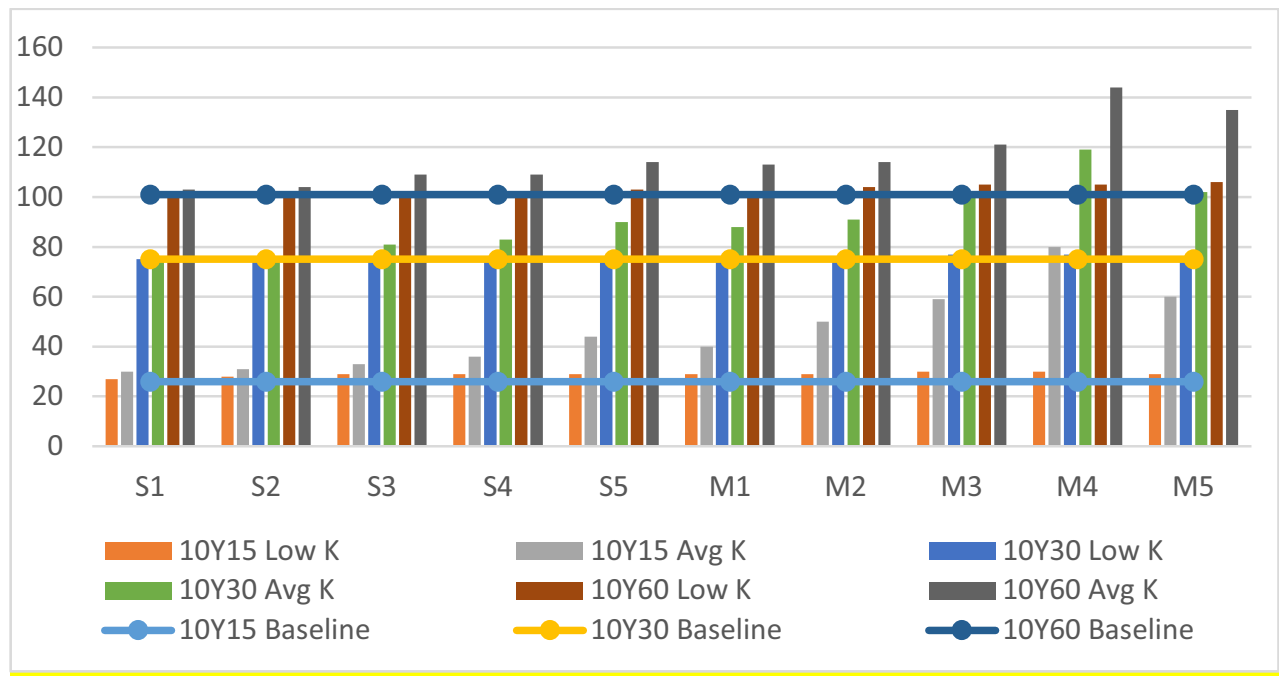

Fig. 4: Number of Flooded Nodes for CSA $1-10$ Year Storm Events

The dewatering scenario for 2 Y 15 Low $\mathrm{K}$ has no significant impact on the network across the various site types and stays at par with the baseline. In contrast, the dewatering flows yielded by 2 Y 15 Average $\mathrm{K}$ indicates increased flooding, which increases with the site type for single site scenarios (S1 to S5) and varies with multi-site scenarios (M1 to M5). Similar observations are made for the 5Y15 and 10Y15 Low K scenarios, with only slight increase in flooding noted. The impact is more significant in the 2Y30 minute and the 2Y60 minute Low $\mathrm{K}$ duration storm scenarios, as increased flooding is noted in comparison to the corresponding baseline. This is further exacerbated for the $2 \mathrm{Y} 30$ \& $2 \mathrm{Y} 60$ Average K scenario types. On the contrary, this is not the case for the 5 year and 10 year storm event frequency of 30 and 60 minutes durations, each of which has a higher baseline flooding to begin with. 


\subsection{General assessment for dewatering discharges to CSAs:}

The results indicates that impact of Dewatering Discharge within CSA 1 area is critical for shorter duration rainfall and is likely to cause more flash flooding for storm events under 30 minute duration storms of shorter frequency of 1 in 2 year to 1 in 5 year. Overall CSA-1 catchment area is more sensitive to flooding and the impact of dewatering discharge within this catchment even under non-critical storm events can result in an increase in flooding incidences. However, as more residential areas contribute to the catchment, the resultant baseline flood incidences will rise and any further dewatering activities will only excarberate the baseline flooding, as seen in CSA 3.

In regards to flooded areas within the catchment, the baseline flooded locations are the most sensitive areas. All the nodes flooded for the baseline, are also flooded in subsequent dewatering scenarios. However, there are additional flooded nodes in dewatering scenarios which are not flooded in the baseline. These nodes are located within the vicinity of the dewatering site (Subcatchment) where additional flows are added, indicating immediate localized flooding during a rainfall event. The flooding pattern indicates that the type of site and the number of active sites, i.e. the dewatering flow quantities play a vital role for changes in flood patterns under simulated rainfall events.

Since CSA-2 is a road only catchment, the catchment is very sensitive to any additional flows beyond its design limits. Similar observations are made in CSA-4, which has a higher design service. The pattern for road only catchments indicate that they are not very sensitive to flooding for non-critical events or events of shorter frequencies and durations, but of larger stroms beyond the design capacity. Although CSA 2 and CSA 4 may present an ideal opportunity to discharge smaller dewatering flows to the catchment, it should be noted that the outfalls are not to the sea but to lagoons and thus controlled discharge has to be undertaken with respect to the capacity of the lagoon itself with enough contingency for the runoff from any potential rainfall event, if the dewatering activity is expected to coincide.

\section{Discussion}

\subsection{Variations in impact}

1. Variations due to Site Type Category: Throughout the simulations, variation in impact of dewatering discharge is observed due to site category. For single site scenarios, it is noted that S1 (Small Residential) and S2 (Compounds) type sites, have minimal impact at low flow rates (Low K) and moderate impact at high flow variations (High K). Similarly, flooding incidences rise in case of S3 (High Rises) and S4 (Commerical) categories, which have moderate (Low K) to high impact (Avg K) in comparison to the baseline for the given storm event. In all the scenarios the largest impact noted was from the S5 (Mega Projects) category. When Multi-site scenarios are evaluated the results are dependent on the contributing sites and the CSA. Overall the impact in multi-site scenario is higher, however the dewatering flows from multiple sites (2+) can actively be discharged and managed, given the contributing flows from two or more sites are low.

2. Variations in Impact due to Location of Construction Site: In all the CSA's analyzed any dewatering induced flooding beyond the baseline was highly localized to the contributing Subcatchment, which is the location of the hypothetical construction site. Since flooding is highly localized the impact will vary depending on the sensitivity of the catchment within the vicinity of the dewatering site.

3. Variations in Impact due to Hydraulic Conductivities \& other Ground Water Properties: The resulting flows yielded by changes in ground properties varies significantly and play 
a role in the contributing flows from dewatering activities. The Dupuit approach provides a range of flows from $0.01 \mathrm{~m}^{3} / \mathrm{s}$ to $0.9 \mathrm{~m}^{3} / \mathrm{s}$ for the simulated scenarios. The variation is largely in part due to the variation in hydraulic conductivity, $\mathrm{K}$ of the soil and the water table level $(\mathrm{m})$ BGL. The range is further divided and varies for the dewatering site properties on the basis of the total excavation area and the excavation depth, both of which have been used to define and categorize sites for the scenarios studied. It should also be noted that if the hydraulic conductivities were greater than the values utilized (Low K at $3 \times 10^{-5} \mathrm{~m} / \mathrm{s}$ and Avg K at $5 \times 10^{-4} \mathrm{~m} / \mathrm{s}$ ), the impact or its variation may be more severe. For smaller catchments, variation in geotechnical properties are expected to remain within a minor range.

4. Variations in Impact due to Storm Events: Variations occur due to both the frequencies of the storm events and the duration of the event. Since the runoff from the catchments will vary for different storm events, the resulting impact from dewatering is also highly dependent on them. It is evident that flooding will occur when runoff generated from contributing catchments exceeds the network's design service levels, which is highly dependent on the Time of Concentration, i.e., the longest run length from upstream to downstream and the properties of the components of the network such as pipe sizes, roughness, leakages, age of network, etc. This is implicated in the form of overall sensitivity of the catchment due to these contributing factors.

\section{Overall impact of dewatering discharge}

The overall impact of dewatering discharge to the surface drainage network for Doha under rainfall conditions is summarized in Table 5 below on the basis of the dewatering flow quantities. The table lists the number of nodes flooded beyond the baseline flooding, for the given storm events. The summary excludes scenarios where there is no baseline flooding in order to deduce the impact of dewatering discharge due to the existing sensitivity of the catchment.

Table 5: Impact Risk Assessment for Dewatering Discharge

\begin{tabular}{|c|c|c|c|c|c|c|c|c|c|}
\hline $\begin{array}{l}\text { Total } \\
\text { Dewatering } \\
\text { Discharge }\end{array}$ & \multicolumn{3}{|c|}{$\begin{array}{c}\text { Impact with } 2 Y \\
\text { Storm Events } \\
\text { (Durations, minutes) }\end{array}$} & \multicolumn{3}{|c|}{$\begin{array}{c}\text { Impact with 5Y } \\
\text { Storm Events } \\
\text { (Durations, minutes) }\end{array}$} & \multicolumn{3}{|c|}{$\begin{array}{c}\text { Impact with } 10 \text { Y Storm } \\
\text { Events } \\
\text { (Durations, minutes) }\end{array}$} \\
\hline $\mathrm{Q}\left(\mathrm{m}^{3} / \mathrm{s}\right)$ & $2 Y 15$ & $2 Y 30$ & $2 Y 60$ & $5 Y 15$ & $5 Y 30$ & $5 Y 60$ & $10 Y 15$ & $10 \mathrm{Y} 30$ & $10 \mathrm{Y} 60$ \\
\hline $0.01-0.05$ & 0 & 7 & 11 & 0 & 6 & 2 & 6 & 0 & 0 \\
\hline $0.06-0.1$ & 2 & 21 & 42 & 10 & 19 & 12 & 18 & 3 & 14 \\
\hline $0.11-0.25$ & 12 & 25 & 46 & 20 & 30 & 20 & 20 & 6 & 19 \\
\hline $0.26-0.5$ & 22 & 29 & 36 & 23 & 30 & 29 & 29 & 22 & 23 \\
\hline $0.51-0.75$ & 32 & 39 & 60 & 35 & 46 & 44 & 54 & 45 & 36 \\
\hline $0.76-1.00$ & 59 & 66 & 86 & 61 & 63 & 66 & 79 & 63 & 54 \\
\hline$>1.00$ & 83 & 102 & 132 & 98 & 105 & 115 & 122 & 110 & 116 \\
\hline
\end{tabular}

\section{Impact Risk Categorization based on Scoring:}

\begin{tabular}{|lll}
\hline & 0-10: & Negligible Impact \\
\hline 11-25: & Low Impact Risk \\
\hline 25-50: & Moderate Impact Risk \\
\hline 50-75: & High Impact Risk \\
\hline 75+: & Severe Impact Risk, discharge not recommended.
\end{tabular}

It is evident that as the flow quantity discharged to the network increases, so does the corresponding flooding regardless of the storm event. The only significant difference is the 
variation in the level of flooding on the basis of the rainfall event. It is also noted that the flooding is negligible for smaller flow quantities below $0.1 \mathrm{~m}^{3} / \mathrm{s}$. However Low Impact Risk exists for frequent storm events of extended durations such as the 2Y60. The exacerbation is minimal for $2 \mathrm{Y} 15$ and 10Y60, the two ends of the spectrum. Both these events show similar behavior, though the latter will have increased flood duration for the incidences than the 2Y15. In case of larger flow quantities in excess of $0.5 \mathrm{~m}^{3} / \mathrm{s}$, the Impact Risk increases significantly from moderate to high and severe flooding. Flows larger than that quantity will expose the network to high Impact risk, with potential localized flooding incidences even without an active rainfall event. It should also be noted that the chart indicates flooding in excess of the baseline, and is essentially a chart depicting the exacerbation of flooding if there is existing potential of flood incidences within the catchment.

\subsection{Recommendations for discharge management}

1. Recycle \& Reuse Dewatering Effluent: This practice falls under 'green site' concept and has been recommended under various frameworks and standards. However recycling of water is not fully utilized on most small scale projects in Qatar [7].

2. Flow management by Relevant Authorities: Potential Flooding due to dewatering discharge on storm drainage can be controlled by effective flow management and setting discharge limits as part of O\&M. Limits will vary depending on the capacity of the network the flows are being discharged to, the number of contributing discharge flows and rainfall conditions.

3. Point of discharge: In addition to controlled discharge, the allocated manhole/point of discharge in relation to its location from outfall can impact the localized flooding and downstream conditions. Allocation of discharge point can help prevent minor flood incidents during rainfall events. Locations prone to flooding during rainfall events and those of high importance should be avoided for dewatering discharge, even for small quantities. If the construction site is large, multiple point of discharges can be allocated to minimize the impact and reduce localized flood incidences.

4. Ground Water Re-injection as a Disposal Option: The Inland Groundwater Basins have reduced significantly over the years [9]. This has forced the country to rely on Desalination to meet potable water demands. Artificial Groundwater Recharge is one of the grand challenges listed out by the Qatar National Vision 2030. There have already been research to identify areas of natural groundwater recharge in Qatar with watershed modelling and recharge using desalinated seawater to maintain current groundwater reserves $[17,18]$. This principle has already been adopted in some sites of Doha Metro Project by Qatar Rail. Outskirts of Doha also provide the opportunity to use lagoons for re-injection instead of pumped recharge, in a very cost effective and natural manner.

5. Groundwater Control via Horizontal Drainage: Horizontal drainage via symbiotic networks of perforated pipes within the existing surface drainage network should be explored. It is understood that some parts of Doha may already have such systems in place [3]. Horizontal drainage can be utilized to maintain a service level of the groundwater table and thus indirectly reduce the discharge flows from construction dewatering activities. These flows are expected to increase as the water table increases in the near future.

\section{Conclusion}

The Dupuit approach was successfully utilized to estimate the construction dewatering flow quantities. The validity of these estimates were also tested by obtaining field data from 
current ongoing sites. Finally, the impact of Construction Dewatering Discharge to the Urban Storm Drainage Networks of Doha city was successfully evaluated using InfoWorks ICM for a total of four different Case Study Areas. The modelling simulated various storm events of varying frequencies and durations. The results arising from these simulations were analyzed and the impact correlation with the total quantity of flows discharged to the network was developed. It is noted that each catchment behaved uniquely on the basis of its runoff surfaces and the total contributing dewatering discharge. There are noticeable differences in the impact due to variations in properties such as hydraulic conductivities, water table levels, catchment types, runoff coefficients, location of site, etc. These properties were also examined and the difference in impact highlighted for the same. On the basis of the results obtained and the data presented, it can be concluded that Dewatering Discharge to the Surface Drainage Network is an overlooked activity that has various risks associated with it. The impact of dewatering discharge can yield significant localized flooding incidences with flows above $0.5 \mathrm{~m}^{3} / \mathrm{sec}$ and minor incidences with flows below $0.5 \mathrm{~m}^{3} / \mathrm{sec}$. The scenarios studied are plausible and to a very large degree pre-existing within the Gulf Region.

\section{References}

1. K.M. Amer, Groundwater for sustainable development: problems, perspectives and challenges. Chapter 3, CRC Press (2008)

2. Ministry of Development Planning and Statistics, Water Statistics In the State of Qatar 2013 (2016)

3. MWH, Qatar Integrated Drainage Master Plan. Final Master Plan Report, Issue 1. Doha (2013)

4. K. Al-Akhras, and A. Al-Miraikhi, From Fundamentals to Applications in Geotechnics Proceedings of the 15th Pan-american Conference on Soil Mechanics and Geotechnical Engineering, IOS Press, 15-18 (2015)

5. N. Hashem, and P. Balakrishnan, Annals of GIS, 21(3), pp.233-247 (2015)

6. J. Bambridge, Rising water table 'challenging' Doha construction. Construction Week Online (2015)

7. Public Works Authority, Construction Dewatering Guidelines Qatar (2014)

8. G. Perez Russo, Definition and implementation of the dewatering work method statement for the Red Line North underground project in Doha-Qatar (2014)

9. G.C. Cox III, International Conference on Case Histories in Geotechnical Engineering. Paper 12 (1984)

10. P. Koudelak, and S. West, Water and Environment Journal, 22(2), pp.81-87 (2008)

11. J.P. Powers, and C.J. Herridge, Construction dewatering and groundwater control: new methods and applications. John Wiley \& Sons (2007)

12. M. Preene, Groundwater control. Design issues, 1185, pp.80-7 (2000)

13. M. Preene, Groundwater lowering in construction: a practical guide to dewatering Vol. 6. CRC Press (2012)

14. A. Al Mamoon, N.E. Joergensen, A. Rahman, and H. Qasem, International Journal of Sustainable Built Environment, 3(1), pp.111-118 (2014)

15. A.S. Bazaraa, and S. Ahmed, Rainfall Characterization in an arid area (1991)

16. Public Works Authority, Qatar Sewerage and Drainage Design Manual, Vol 3 (2005)

17. H. Baalousha, MODSIM2015, 21st International Congress on Modelling and Simulation. pp. 2026-2032 (2015)

18. J.O. Kimrey, Proposed artificial recharge studies in northern Qatar No. 85-343. (1985) 